\title{
Reference birthweight range for multiple birth neonates in Japan Noriko Kato*
}

\author{
Address: Department of Health Promotion and Research, National Institute of Public Health, 2-3-6 Minami, Wako-shi, Saitama, $351-0197$ Japan \\ Email: Noriko Kato* - kato@niph.go.jp \\ * Corresponding author
}

Published: 03 February 2004

BMC Pregnancy and Childbirth 2004, 4:2
Received: 10 June 2003

Accepted: 03 February 2004

This article is available from: http://www.biomedcentral.com/I47I-2393/4/2

(C) 2004 Kato; licensee BioMed Central Ltd. This is an Open Access article: verbatim copying and redistribution of this article are permitted in all media for any purpose, provided this notice is preserved along with the article's original URL.

\begin{abstract}
Background: A reference range for the birthweight of multiple births neonates is necessary for the assessment for intrauterine growth.

Methods: Pairs of multiple births were identified by birthplace, the ages of the parents, gestational age, and the year and month of birth. We studied a total of 32,232 livebirth-livebirth pairs of twins, 1894 triplet live births, and 206 quadruplet live births.

Results: The median birthweight of males, taking gestational age into account, was ca. $0.05 \mathrm{~kg}-0.1$ $\mathrm{kg}$ heavier than that of females. Compared to singleton neonates, the median birthweight of twins was ca. $0.15 \mathrm{~kg}$ smaller at the gestational age of 34 weeks, increasing to ca. $0.5 \mathrm{~kg}$ at 42 weeks of gestation. As for birth order, the mean birthweight of the first-born twin was heavier than that of the second-born. The standard deviation of birthweight was larger for second-born twins. The birthweight of twins from multiparous mothers was greater than those from primiparous mothers. The median birthweight according to gestational age was found to be the greatest in twins, lower in triplets and the lowest in quadruplets. In triplets, the $50^{\text {th }}$ percentile was $0.08 \mathrm{~kg}$ heavier in boys than for girls.
\end{abstract}

Conclusion: Our results can be used for assessment of birthweight of multiple births in Japan.

\section{Background}

Since the introduction of assisted reproductive technology, the rate of multiple births has been increasing rapidly in Japan [1]. A reference range for the birthweight of multiple births neonates is necessary for the assessment for intrauterine growth. Studies on the birthweight of twins have been conducted in many countries [2-5], and some of these studies have used hospital birth records [6].

The aim of this research is to present a methdologic approach to constructing birthweight reference ranges for multiples based on Japanese birth certificates, and also to clarify how the population-based data are useful for creation of birthweight reference for multiple births. Results of the research would be helpful to perinatologists for evaluating intrauterine growth of multiples, and for evaluating twin percentile rank at birth.

\section{Methods}

In Japan, birth, death, and stillbirth certificates are currently stored in data files on magnetic tapes. These certificates are filed in the city health department and changed into computerized files in Ministry of Health, Labour and Welfare of Japan. This database contains sex, birthweight, gestational age, parity, ages of father and mother. The database is limited because twins are not linked to each other and information about mode of conception ie. spontaneous or iatrogenic is not available from database. 


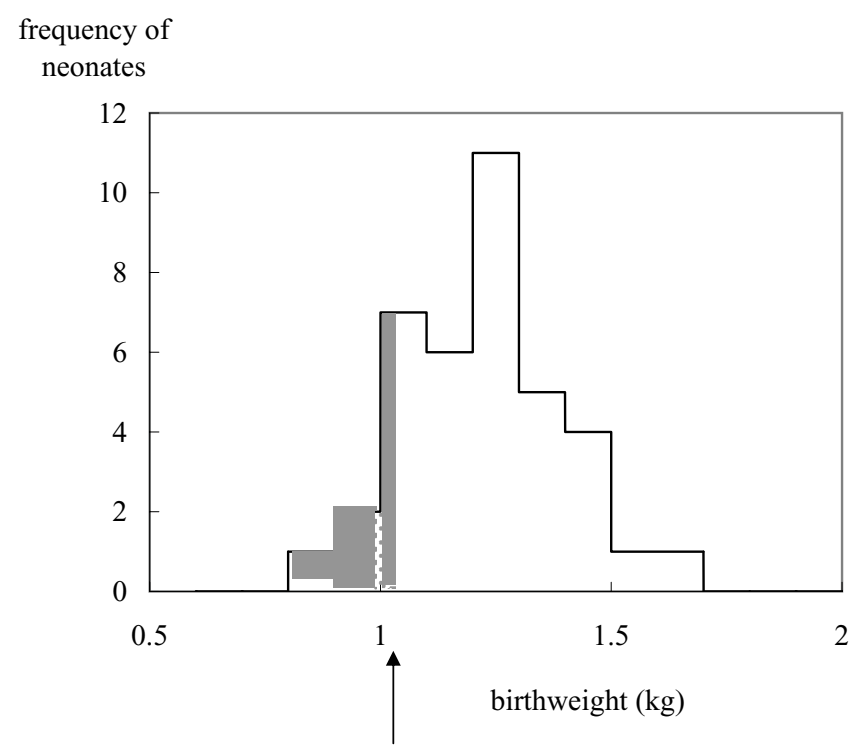

10th percentile birthweight value is here. Shadowed area is $10 \%$ of the total area.

\section{Figure I}

Calculation of $10^{\text {th }}$ birthweight percentile value from histogram of birthweight from male triplets with gestation of 29 weeks
From these tapes, we identified 66,005 twins, 1,894 triplets and 206 quadruplets who were born in Japan between 1988 and 1991. Because mean birthweight of Japanese neonates is declining year by year [7], comparison of birthweight between multiple births and singletons[8] should be done between the birth of the same period, which is around the year 1990.

Unlikely combinations of birthweight and gestational age were defined within each stratum of multiplicity, gender and gestational age as recorded with birthweight more than 3SD from the mean.

Because the database was limited and twins were not linked to each other, these twins were arranged into pairs in order to determine twin pairs are like-sexed or unlikesexed. Both pairs were born in the same municipality, within 10 days of each other to parents of the same age. By this method, 32,232 livebirth-livebirth pairs of twins were selected for analysis in this study. According to Weinberg's formula [9], the estimated values of monozygotic and dyzygotic pairs were 18,830 and 13,402 respectively.

To calculate the mean birthweight and the standard deviation, 50 grams were added to the recorded birth weight because birth weight is recorded every 100 grams, which does not exceed actual birthweight value. To calculate the mean gestational age and the standard deviation, 3.5 days were added to the recorded gestational age because gestational age is recorded at full weeks which do no exceed actual gestational age.

Significance of differences in mean values of gestational age and birthweight was statistically analyzed using student t-test for 2 groups and ANOVA for 3 groups and more. Significance of differences in median values was not statistically tested.

Figure 1 illustrates the $10^{\text {th }}$ birthweight percentile value calculated from a histogram of birthweights from 38 cases of male triplets with gestation of 29 weeks. The number of the cases was smaller than that of twins in each gestational week. Shadowed area corresponds to lower $10 \%$ of relative cumulative frequency. The right side of the shadowed area corresponds to $10^{\text {th }}$ percentile value of male triplets with gestation of 29 weeks. $50^{\text {th }}$ and $90^{\text {th }}$ percentile birthweight values were determined in the same way. The number of subjects used to calculate these values is shown on Table 1. Gestational age of 42 weeks is certainly too long for twins, but they are not supposed to be caused by errors in filing data but are considered to be clinically rare cases.

The percentiles obtained for twins were smoothed using the cubic spline function [10], while those of triplets and quadruplets were smoothed using quadratic or cubic polynomial functions with the smaller sum of the square residuals.

\section{Results}

The mean gestational age and birthweight were analyzed according to gender, birth order, parity, and gender combination within the pair (Table 2). Female, multiparous, and unlike-sexed pairs were found to exhibit the longer gestational age. Male, multiparous, $1^{\text {st }}$ born and unlikesexed pairs were found to have heavier birthweights. Differences by parity were twice as large as sex difference. Males of unlike-sexed pairs exhibited the heaviest birthweight, followed by males of unlike-sexed pairs, females of unlike-sexed pairs, females of like-sexed pairs. Differences of mean values between/among groups stated above were all statistically significant.

Birthweight according to the gestational age of twins as calculated in our study are shown in Figures 2 and 3. Males were heavier than females, and average difference through overall gestational ages was 70 grams for primipara and 90 grams for multipara (Table 3).

Median birthweight curves of multiple births were compared with that of singletons as reported by Ogawa [8]. At 
Table I: Number of subjects analyzed from each gestational week

\begin{tabular}{|c|c|c|c|c|c|c|}
\hline \multirow{2}{*}{$\begin{array}{l}\text { gestational age } \\
\text { (weeks) }\end{array}$} & \multicolumn{2}{|c|}{ Twins } & \multicolumn{2}{|c|}{ triplets } & \multicolumn{2}{|c|}{ quadruplets } \\
\hline & male & female & male & female & male & female \\
\hline 24 & 76 & 64 & 14 & 14 & 3 & 1 \\
\hline 25 & 121 & 111 & 11 & 7 & 5 & 6 \\
\hline 26 & 105 & 116 & 7 & 11 & & \\
\hline 27 & 176 & 145 & 14 & 25 & 3 & 7 \\
\hline 28 & 208 & 196 & 26 & 35 & 13 & 11 \\
\hline 29 & 211 & 204 & 38 & 40 & 17 & 11 \\
\hline 30 & 309 & 287 & 33 & 27 & 15 & 12 \\
\hline 31 & 427 & 325 & 51 & 52 & 13 & 15 \\
\hline 32 & 673 & 549 & 59 & 54 & 10 & 8 \\
\hline 33 & 906 & 844 & 109 & 108 & 10 & 7 \\
\hline 34 & 1366 & 1356 & 115 & 123 & 12 & 11 \\
\hline 35 & 2306 & 2122 & $|4|$ & $|3|$ & 3 & 5 \\
\hline 36 & 4257 & 4132 & 143 & 154 & 2 & 2 \\
\hline 37 & 7276 & 7128 & 89 & 96 & & \\
\hline 38 & 6963 & 7343 & 41 & 66 & & \\
\hline 39 & 4358 & 4632 & 16 & 21 & & \\
\hline 40 & 1924 & 2135 & & 1 & & \\
\hline 41 & 456 & 470 & & & & \\
\hline 42 & 39 & 39 & & & & \\
\hline
\end{tabular}

Table 2: gestational age and birthweight of twins according to variables

\begin{tabular}{|c|c|c|c|c|}
\hline gestational age & no. of cases & mean (weeks) & standard deviation (weeks) & significance of difference \\
\hline total & 64464 & 37.2 & 2.7 & \\
\hline male & 32211 & 37.2 & 2.6 & $* * *$ \\
\hline female & 32253 & 37.3 & 2.6 & \\
\hline primipara & 29106 & 37.1 & 2.8 & $* * *$ \\
\hline multipara & 35358 & 37.3 & 2.6 & \\
\hline like-sexed male & 25510 & 37.1 & 2.7 & $* * *$ \\
\hline like-sexed female & 25552 & 37.3 & 2.7 & \\
\hline unlike-sexed & 13402 & 37.4 & 2.6 & \\
\hline birthweight & no. of cases & mean $(\mathrm{kg})$ & standard deviation $(\mathrm{kg})$ & \\
\hline total & 64447 & 2.39 & 0.51 & \\
\hline male & 32202 & 2.43 & 0.51 & $* * *$ \\
\hline female & 32245 & 2.36 & 0.50 & \\
\hline primipara & 29098 & 2.31 & 0.50 & $* * *$ \\
\hline multipara & 35349 & 2.46 & 0.50 & \\
\hline Ist twins & 32156 & 2.42 & 0.50 & $* * *$ \\
\hline 2nd twins & 32153 & 2.36 & 0.51 & \\
\hline like-sexed male & 25501 & 2.41 & 0.52 & $* * *$ \\
\hline like-sexed female & 25545 & 2.35 & 0.50 & \\
\hline unlike-sexed male & 6701 & 2.49 & 0.50 & \\
\hline unlike-sexed female & 6700 & 2.39 & 0.48 & \\
\hline
\end{tabular}

$* * * \mathrm{p}<0.001$ 
birthweight $(\mathrm{kg})$

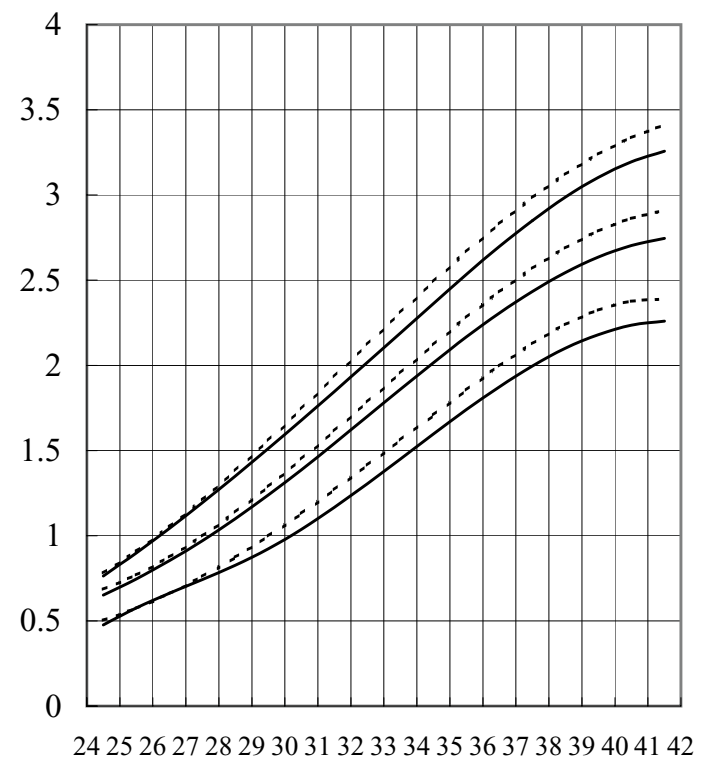

gestational age (weeks)

\section{Figure 2}

Birthweight percentile curves of twins (male) dotted lines: multipara solid lines: primipara The 3 lines of each category correspond to the 10th, 50th and 90th percentiles birthweight $(\mathrm{kg})$

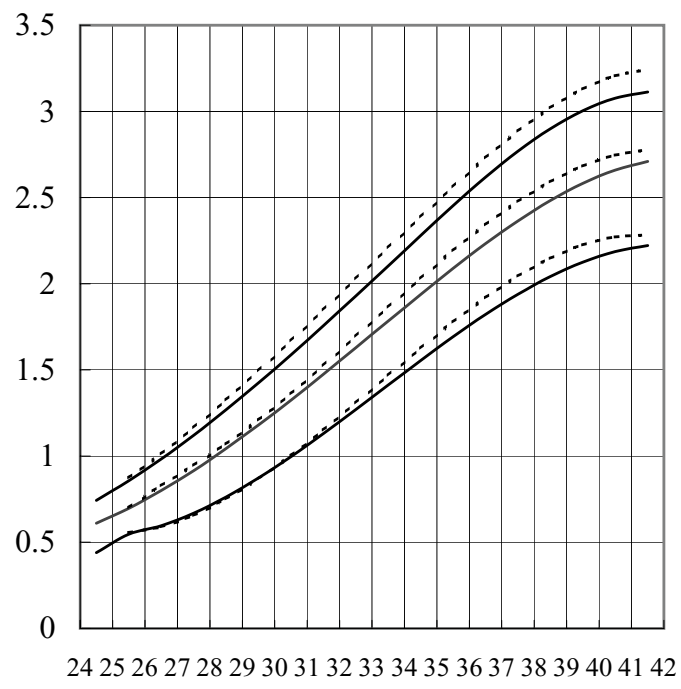

gestational age (weeks)

\section{Figure 3}

Birthweight percentile curves of twins (female) dotted lines: multipara solid lines: primipara The 3 lines of each category correspond to the 10th, 50th and 90th percentiles gestational ages of less than 34 weeks, the mean birthweight of twins was 150 grams lighter than that of singletons. This difference increased to 500 grams at 40 weeks of gestation.

In multiple birth neonates, the median birthweight according to gestational age was found to be the greatest in twins, followed by triplets and quadruplets (Figures 4 and 5).

In triplets, the $50^{\text {th }}$ percentile of birthweight was $0.08 \mathrm{~kg}$ heavier in boys than in girls (Figure 6, Table 4). In quadruplets, only a small difference was observed between boys and girls, except for 27 weeks of gestation (Figure 7 and Table 4). For triplets and quadruplets, sample size was too small for calculation of birthweight percentile values by parity and also by gestational age less than 27 weeks.

\section{Discussion}

Population-based data are used in the analysis in many countries. Reference birthweight is calculated from population-based data in Canada [2]. Data were obtained from vital statistics of health department birth registrations. Birth weight percentile values were calculated with each stratum of multiplicity, gender, and gestational age. The population-based reference birthweight was also created in Norway[4] from Medical Birth Registry. Percentile value for each gestational week was smoothed assuming a normal distribution. These studies clarified that population-based data are useful for production of reference birthweight.

We found that the birthweight of twins born after 34 weeks of gestation was greater than that calculated by Fukuda [6]. This discrepancy is thought to be because Fukuda obtained data from a hospital specializing in high risk pregnancy, which are not suitable for creating reference which IUGR of multiple birth is diagnosed. Population-based data is with large sample size and with less bias as high risk pregnancy, while quality of data such as gestational age is higher in hospital-based data.

Gestational age is thought to be influenced by gender, placentation, zygosity and parity. Preterm delivery of boys is thought to be related to the production of androgenic hormones, which disturbs the endocrine balance that controls the initiation of labor[12]. According to Bleker [11], dichorial twins exhibited a longer gestational age 


\section{birthweight (kg)}

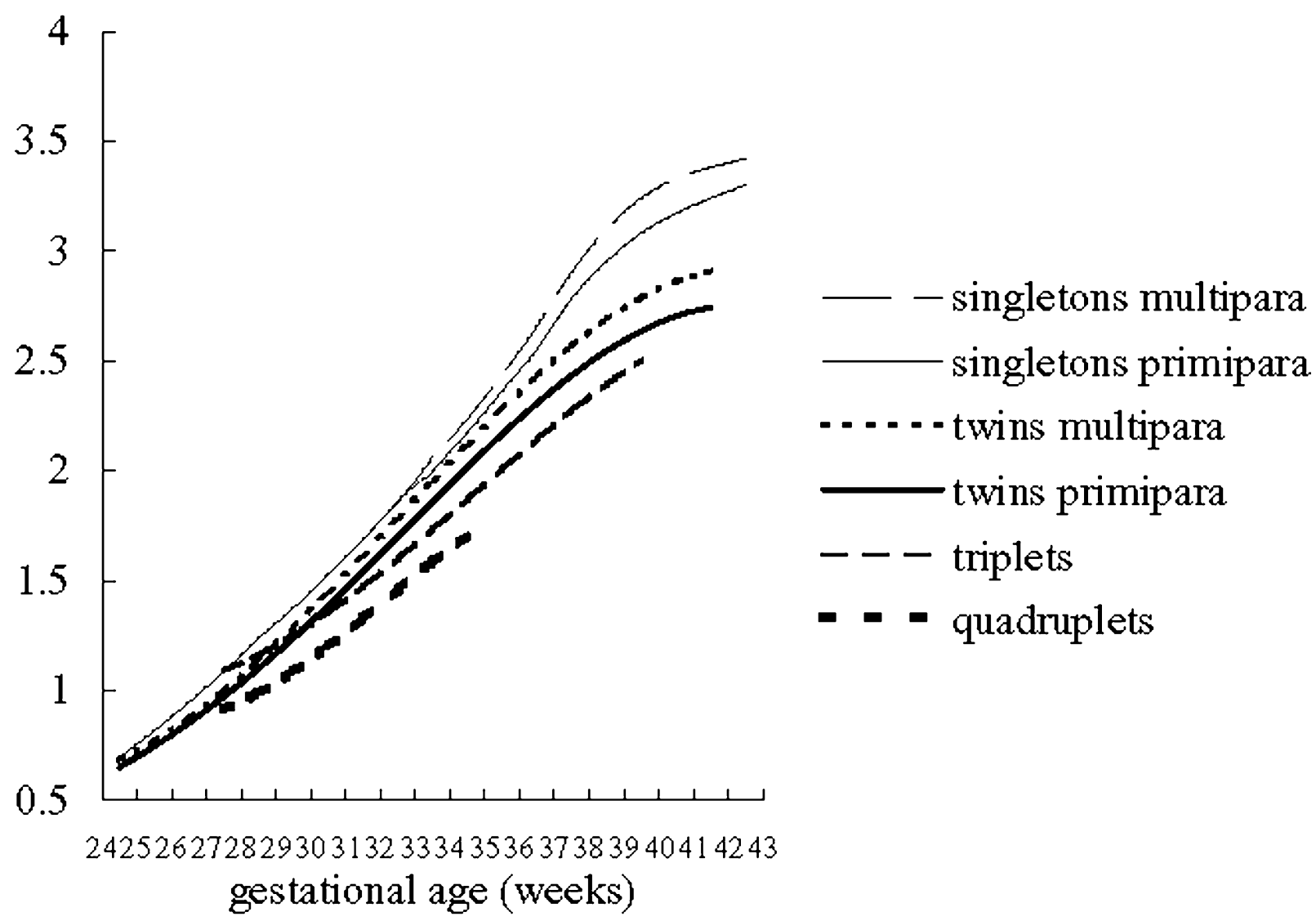

Figure 4

Median birthweight of neonates of multiple births (male)

than monochorial twins, and multiparous twins exhibited longer gestational ages than primiparous twins.

MacGillivray [12] found that the gestational age of $M Z$ is shorter than that of $\mathrm{DZ}$, and that the gestational ages of males is shorter than that of females. These results are consistent with those of our study. With zygosity, preterm delivery of $\mathrm{MZ}$ often accompanies preterm membrane rupture due to either acute hydroamnios or weakness in the membranes [12]. More than half of $\mathrm{MZ}$ twins are with monochorionic membranes and monochorionic membranes are weak because they are shared by both twins, thus shortening the gestational ages of $\mathrm{MZ}$ twins [12].

Our study shows that gestational age of like-sexed twins is shorter than that of unlike-sexed, and that of males is shorter than females. In our data, unlike-sexed twins are all $\mathrm{DZ}$, and $73.7 \%$ of like-sexed twins are $\mathrm{MZ}$ calculated from Weinberg's formula [9]. Average gestational age of like-sexed twins is more similar to MZ in our study than to DZ.

With parity, the amount of distention tolerated by the uterus at a given time during pregnancy is greater in multiparae than in primiparae whose gestational ages are shorter [11].

Median birthweight values of Japanese twins were compared with those of singletons derived from database in which birthweights were rounded to $10 \mathrm{~g}$.

According to the report by Karn [13], twins exhibited greater weight deficit than singletons after 30 weeks gestation. According to the report in Naeye [14], after 33 weeks gestation, the mean weight of twins is markedly less than that of singletons. Blecker et al [11] reported that the difference in weight between twins and singletons at 39 to 40 weeks is about 600 grams. 


\section{birthweight $(\mathrm{kg})$}

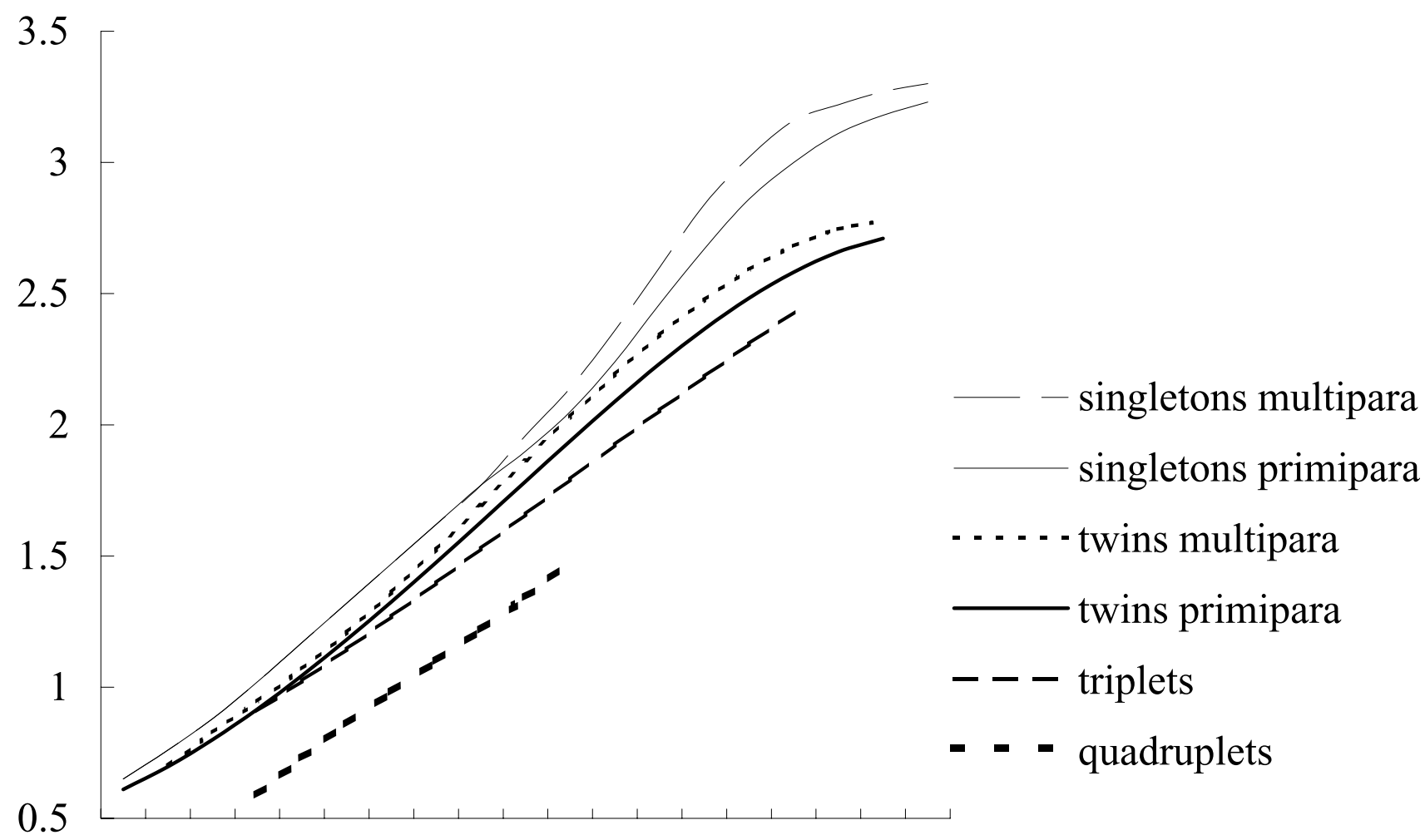

$\begin{array}{llllllllllllllllllll}24 & 25 & 26 & 27 & 28 & 29 & 30 & 31 & 32 & 33 & 34 & 35 & 36 & 37 & 38 & 39 & 40 & 41 & 42 & 43\end{array}$

\section{gestaional age (weeks)}

Figure 5

Median birthweight of neonates of multiple births (female)

The median birthweight curves of the subjects in this study, which are similar to those of McKewn et al [15], suggest that growth limitation within the uterus becomes more marked with increasing numbers of fetuses. Besides, median birthweight curves created by McKewn et al are not population-based and do not contain iatrogenic multiples.

According to the report by Naeye et al [14], the mean birthweight of males is approximately 80 grams heavier than that of that of females at 24-26 weeks of gestation, increasing to 150 heavier at 40 weeks of gestational age. The difference of birthweight between males and females was found to differ less in twins than in singletons [11].
Our study found that this sex difference was almost the same within twins and singletons (Figures 2 and 3).

The birthweight of twins differs according to sex composition. Unlike-sexed twins were found to be $63 \mathrm{~g}$ to $141 \mathrm{~g}$ heavier than like-sexed twins $[13,16,17]$.

The influence of sex on birthweight is less significant than the influence of sex combination, as reported by Corney et al [17]. Corney et al also found that monochorial twins are lighter than dichorial twins [17], and that monochorial twins use their placenta less effectively. The low birthweight of $\mathrm{MZ}$ is attributed to the placenta itself [18]. 
birthweight $(\mathrm{Kg})$

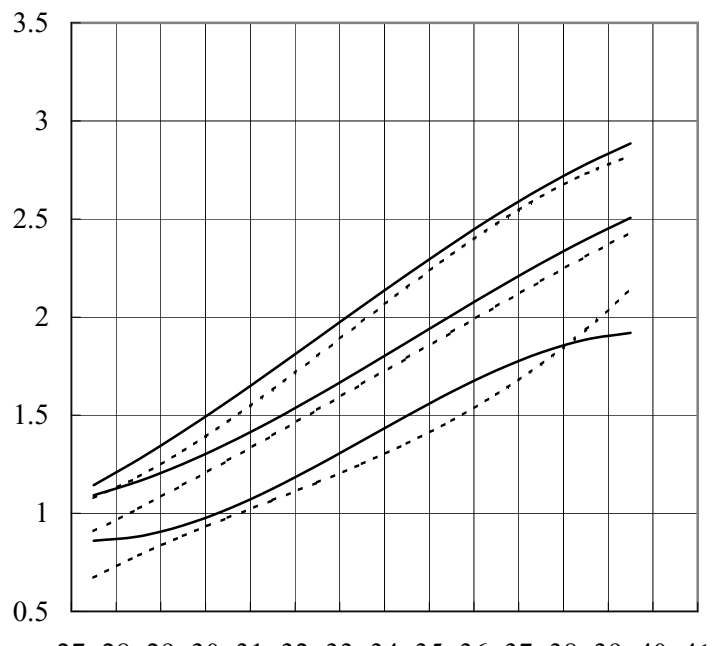

$\begin{array}{lllllllllllllll}27 & 28 & 29 & 30 & 31 & 32 & 33 & 34 & 35 & 36 & 37 & 38 & 39 & 40 & 41\end{array}$

gestational age (weeks)

\section{Figure 6}

Birthweight percentile curves of triplets dotted lines: multipara solid lines: primipara The 3 lines of each category correspond to the 10th, 50th and 90th percentiles

Bleker [11] reported that the influence of parity to birthweight is grater than that of gender. They found that multiparous neonates were heavier at birth because of increased ability of the uterus to distend that subsequently permits more intrauterine growth. According to the report by Asaka [19], the mean birthweight of first-born twins is $52 \mathrm{~g}$ larger than that of second-born twins, a result consistent with our findings.

According to the concept of "total fetal mass", in which all the fetuses are included, it is actually greater in twins and higher order multiples. In this point of view, Multiples as total fetal mass are actually growth promoted. Smaller size is considered to reflect fetal adaptation to the inability of the uterus to nurture the larger fetal mass [20].

The fetus is affected by the limitation of uterine expansion in the later gestational weeks, but any growth retardation is recovered after birth [21]. Intrauterine growth standards are referred to in the assessment of birthweight according to gestational age. If birthweight reference for singletons are used for the assessment of intrauterine growth of multiple births, considerable part of them are misclassified as IUGR even if they are with adequate intrauterine growth birthweight $(\mathrm{kg})$

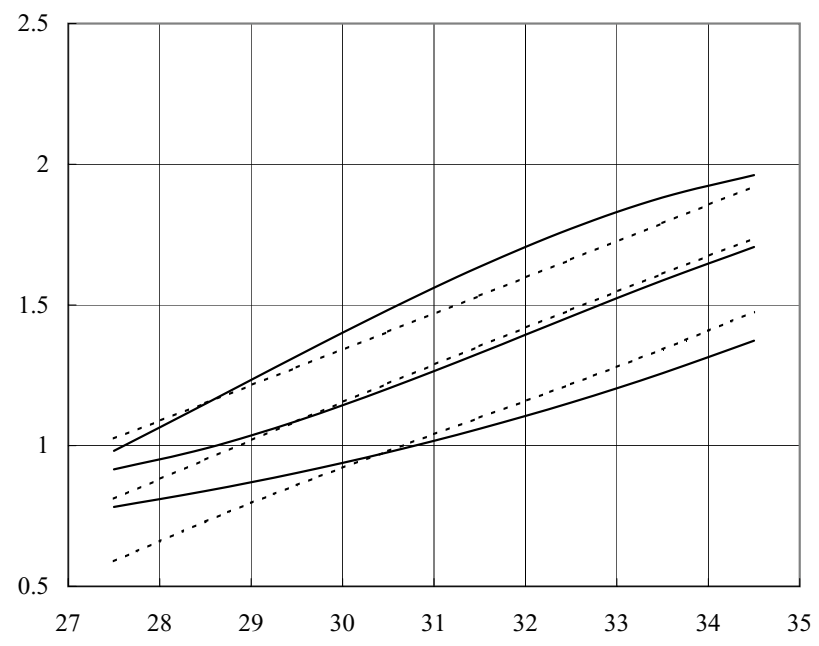

gestational age (weeks)

Figure 7

Birthweight percentile curves of quadruplets dotted lines: multipara solid lines: primipara The 3 lines of each category correspond to the 10th, 50th and 90th percentiles

as multiples. This report showed a birthweight reference range for exclusive use in the assessment of multiple births. This study considers only live-born twins. Analysis of the birthweight of twins who die in utero is in progress.

\section{Conclusions}

Birthweight reference curves for multiple births can be developed using population-based data better than using other kind of data sources. Results of the present study can be used for assessment of multiple births whether they are really growth retarded or with appropriate intrauterine growth as mutiples. These results are helpful to clinicians to provide adequate care for the multiples.

\section{Competing interests}

None declared.

\section{Author's contributions}

NK conceived of the study, provided study design, conducted analysis and prepared the manuscripts. 
Table 3: Birthweight percentiles of twins (kg)

\begin{tabular}{|c|c|c|c|c|c|c|c|c|c|c|c|c|}
\hline \multirow{3}{*}{$\begin{array}{l}\text { gestation } \\
\text { al age } \\
\text { (week) }\end{array}$} & \multicolumn{6}{|c|}{ male } & \multicolumn{6}{|c|}{ female } \\
\hline & \multicolumn{3}{|c|}{ primipara } & \multicolumn{3}{|c|}{ multipara } & \multicolumn{3}{|c|}{ primipara } & \multicolumn{3}{|c|}{ multipara } \\
\hline & I0th & 50th & 90 th & I0th & 50th & 90 th & IOth & 50 th & 90 th & I0th & 50 th & 90th \\
\hline 24 & 0.476 & 0.651 & 0.763 & 0.504 & 0.686 & 0.782 & 0.440 & 0.610 & 0.743 & & & \\
\hline 25 & 0.576 & 0.746 & 0.899 & 0.574 & 0.770 & 0.909 & 0.547 & 0.697 & 0.857 & 0.556 & $0.70 \mathrm{I}$ & 0.874 \\
\hline 26 & 0.662 & 0.853 & 1.043 & 0.660 & 0.875 & 1.053 & 0.596 & 0.800 & 0.983 & 0.590 & 0.828 & 1.013 \\
\hline 27 & 0.743 & 0.971 & 1.194 & 0.761 & 0.999 & 1.212 & 0.669 & 0.916 & 1.121 & 0.656 & 0.946 & 1.165 \\
\hline 28 & 0.827 & 1.100 & 1.350 & 0.874 & 1.138 & 1.382 & 0.762 & 1.044 & 1.269 & 0.751 & 1.070 & 1.326 \\
\hline 29 & 0.923 & 1.239 & 1.512 & 0.999 & 1.289 & 1.560 & 0.873 & 1.181 & 1.425 & 0.868 & 1.209 & 1.495 \\
\hline 30 & 1.037 & 1.387 & 1.678 & 1.131 & 1.450 & 1.745 & 0.997 & 1.325 & 1.588 & 1.003 & 1.362 & 1.669 \\
\hline 31 & 1.166 & 1.542 & 1.846 & I.27I & 1.616 & 1.934 & 1.130 & 1.475 & 1.756 & 1.151 & 1.525 & 1.848 \\
\hline 32 & 1.305 & 1.701 & 2.018 & 1.415 & 1.786 & 2.123 & 1.270 & 1.629 & 1.929 & 1.308 & 1.694 & 2.028 \\
\hline 33 & 1.450 & 1.860 & 2.190 & 1.562 & 1.955 & 2.310 & 1.413 & 1.784 & 2.104 & 1.468 & 1.864 & 2.209 \\
\hline 34 & 1.597 & 2.016 & 2.363 & 1.709 & 2.121 & 2.492 & 1.555 & 1.938 & 2.280 & 1.626 & 2.031 & 2.387 \\
\hline 35 & 1.740 & 2.167 & 2.534 & 1.855 & 2.281 & 2.667 & 1.692 & 2.089 & 2.453 & 1.778 & 2.192 & 2.562 \\
\hline 36 & 1.874 & 2.307 & 2.698 & 1.997 & 2.432 & 2.832 & 1.822 & 2.233 & 2.618 & 1.919 & 2.342 & 2.730 \\
\hline 37 & 1.996 & 2.434 & 2.850 & 2.127 & 2.569 & 2.985 & 1.939 & 2.365 & 2.769 & 2.044 & 2.476 & 2.885 \\
\hline 38 & 2.100 & 2.545 & 2.987 & 2.239 & 2.689 & 3.121 & 2.042 & 2.483 & 2.899 & 2.147 & 2.591 & 3.020 \\
\hline 39 & 2.180 & 2.636 & 3.103 & 2.324 & 2.788 & 3.240 & 2.125 & 2.582 & 3.004 & 2.225 & 2.682 & 3.129 \\
\hline 40 & 2.236 & 2.704 & 3.195 & 2.377 & 2.863 & 3.337 & 2.187 & 2.659 & 3.077 & 2.271 & 2.746 & 3.206 \\
\hline $4 I$ & 2.260 & 2.745 & 3.257 & 2.389 & 2.909 & $3.4 I I$ & 2.222 & 2.710 & 3.113 & 2.282 & 2.777 & 3.243 \\
\hline
\end{tabular}

Table 4: Birthweight percentiles of supertwins (kg)

\begin{tabular}{|c|c|c|c|c|c|c|c|c|c|c|c|c|}
\hline \multirow{3}{*}{$\begin{array}{l}\text { gestational age } \\
\text { (weeks) }\end{array}$} & \multicolumn{6}{|c|}{ triplets } & \multicolumn{6}{|c|}{ quadruplets } \\
\hline & \multicolumn{3}{|c|}{ male } & \multicolumn{3}{|c|}{ female } & \multicolumn{3}{|c|}{ male } & \multicolumn{3}{|c|}{ female } \\
\hline & 10th & 50th & 90th & 10th & 50 th & 90th & 10th & 50 th & 90th & 10th & 50th & 90th \\
\hline 27 & 0.860 & 1.092 & 1.143 & 0.672 & 0.909 & 1.079 & 0.782 & 0.916 & 0.982 & 0.589 & 0.812 & 1.025 \\
\hline 28 & 0.882 & 1.163 & 1.274 & 0.784 & 1.024 & 1.186 & 0.839 & 0.990 & 1.149 & 0.730 & 0.950 & 1.151 \\
\hline 29 & 0.938 & 1.252 & 1.418 & 0.884 & I.145 & 1.317 & 0.903 & 1.088 & 1.318 & 0.860 & 1.087 & 1.278 \\
\hline 30 & 1.021 & 1.357 & I.57| & 0.977 & 1.270 & 1.467 & 0.977 & 1.203 & 1.483 & 0.981 & 1.221 & 1.405 \\
\hline 31 & 1.125 & 1.474 & 1.730 & 1.067 & 1.398 & 1.630 & 1.060 & 1.329 & 1.636 & 1.100 & 1.353 & 1.533 \\
\hline 32 & 1.244 & 1.601 & 1.892 & 1.157 & 1.528 & 1.802 & 1.153 & 1.459 & I.77I & 1.219 & 1.483 & 1.662 \\
\hline 33 & 1.370 & 1.734 & 2.056 & 1.252 & 1.660 & 1.977 & 1.258 & 1.587 & 1.882 & 1.342 & 1.611 & 1.791 \\
\hline 34 & 1.497 & $1.87 \mid$ & 2.216 & 1.355 & 1.792 & 2.151 & 1.373 & 1.706 & 1.961 & 1.475 & 1.736 & 1.921 \\
\hline 35 & 1.619 & 2.008 & 2.372 & $1.47 \mid$ & 1.924 & 2.318 & & & & & & \\
\hline 36 & 1.729 & 2.144 & 2.520 & 1.604 & 2.055 & 2.474 & & & & & & \\
\hline 37 & 1.820 & 2.274 & 2.656 & 1.758 & 2.183 & 2.613 & & & & & & \\
\hline 38 & 1.886 & 2.396 & 2.779 & 1.937 & 2.309 & 2.730 & & & & & & \\
\hline 39 & 1.920 & 2.506 & 2.885 & 2.144 & 2.430 & 2.821 & & & & & & \\
\hline
\end{tabular}




\section{Acknowledgements}

We thank the personnel of the Department of Statistics and Information, Ministry of Health, Labor and Welfare of Japan for copying the magnetic tape data on birth and death certificates. This work was supported by MEXT. KAKENHI (I3670407).

\section{References}

I. Imaizumi Y: Recent and long-term trends of multiple birth rates and influencing factors in Japan. Journal of Epidemiology 1994, 4:103-109.

2. Arbuckle TE, Wilkins R, Sherman GJ: Birth weight percentiles by gestational age in Canada. Obstet Gynecol 1993, 81:39-48.

3. Buckler JM, Green M: Birth weight and head circumference standards for English twins. Arch Dis Child 1994, 71:516-521.

4. Glinianaia SV, Skjaerven R, Magnus P: Birthweight percentiles by gestational age in multiple births. A population-based study of Norwegian twins and triplets. Acta Obstet Gynecol Scand 2000, 79:450-458.

5. Min SJ, Luke B, Gillespie B, Min L, Newman RB, Mauidin JG, Witter FR, Salman FA, O'Sullivan MJ: Birth weight references for twins. Am J Obstet Gynecol 2000, I 82: I250-1257.

6. Fukuda M: Clinical study of twins. Part I. Intrauterine growth curve of twins. Japanese Journal of Neonatology 1990, 26:366-37I.

7. Mother's \& Children's Health and Welfare Association: Maternal and Child Health Statistics of Japan Tokyo: Mother's \& Children's Health Organozation; 2003.

8. Ogawa $Y$, Iwamura T, Kuriya N, Nishida $H$, Takeuchi H, Yakada M, Itabashi K, Imura S, Isobe K: Birth size standards by gestational age for Japanese neonates. Japanese Journal of Neonatology 1998, 34:624-642.

9. Weinberg W: Beiträge zur Physilogie und Pathologie der Wehrlingsgeburten beim Menchen. Arch Ges Physiol 1901, 88:346-430.

10. Cline AK: Scalar- and planer-valued curve fitting using splines under tension. Communications of the Association for Computing Machinery 1974, I 7:218-220.

I I. Bleker OP, Breur W, Huidekoper BL: A study of birth weight, placental weight and mortality of twins as compared to singletons. British Journal of Obstetric and Gynecology 1979, 86: III-II8.

12. MacGillivray I: Determinants of Birthweight of Twins. Acta Genet Med Gemellol 1983, 32:151-157.

13. Karn MN: Birth weight and length of gestation of twins, together with maternal age, parity, and survival rate. Ann Eugen 1952, 16:365-377.

14. Naeye RL, Benirschke K, Hangstrom JWC, Marcus C: Intrauterine growth of twins as estimate from liveborn birth-weight data. Pediatrics 1966, 37:409-4I6.

15. McKeown T, Record RG: Observations on foetal growth in multiple pregnancy in man. J Endocrinol 1952, 8:386-40I.

16. Corney G, Robson EB, Strong S): The effect of zygosity on the birth weight of twins. Ann Hum Genet Lond 1972, 36:45-59.

17. Corney G, Thompson B, Campbell DM, MacGillivray I, Seedburgh D, Timlin D: The effect of zygosity on the birth weight of twins in Aberdeen and Northeast Scotland. Acta Genet Med Gemellol 1979, 28:353-360.

18. Ramos-Arroyo MA, Ulbright TM, Yu PL, Christian C: Twin study: relationship between birth weight, zygosity, placentation, and pathologic placental changes. Acta Genet Med Gemellol I 988, 37:229-238.

19. Asaka A, Imaizumi Y, Inouye E: Analysis of multiple births in Japan III. Analysis of factors affecting birth weight of twins and triplets. Jpn J Human Genet 1980, 25:65-7I.

20. Oleszczuk AK, Oleszczuk JJ, Keith LG: Defining the high-risk nature of triplet pregnancies. Int J Fertil Womens Med 2002, 47:182-190.

21. Ooki S, Asaka A: Growth and development of twins(4) -An analysis of birth weight, height, head circumference and chest circumference of twins according to gestational weeks at birth--. The Journal of Child Health 1992, 5 I:697-720.

\section{Pre-publication history}

The pre-publication history for this paper can be accessed here:

http://www.biomedcentral.com/1471-2393/4/2/prepub
Publish with Biomed Central and every scientist can read your work free of charge

"BioMed Central will be the most significant development for disseminating the results of biomedical research in our lifetime. "

Sir Paul Nurse, Cancer Research UK

Your research papers will be:

- available free of charge to the entire biomedical community

- peer reviewed and published immediately upon acceptance

- cited in PubMed and archived on PubMed Central

- yours - you keep the copyright

Submit your manuscript here:

http://www.biomedcentral.com/info/publishing_adv.asp
BiolMedcentral 